\title{
Relationship between personal care products usage and triclosan exposure: the second Korean National Environmental Health Survey (KoNEHS 2012-2014)
}

\author{
Minkyu Park', Seyoung Kim, Yeji Kim', Do Jin Nam, Jae-Hong Ryoo ${ }^{1}$ and Sinye $\operatorname{Lim}^{1,2^{*}}$ (D)
}

\begin{abstract}
Background: We aimed to find the exposure level of triclosan (TCS), a known endocrine disruptor, related to the use of personal care products using a nationally representative data of the general population in Korea.

Methods: This study included data of 6288 adults aged 19 years and older (2692 men, 3596 women), based on the Second Korean National Environmental Health Survey (KoNEHS 2012-2014). The data were divided according to gender. The frequency and proportion of each variable were determined by dividing participants into two groups based on the top 75th percentile concentration of urinary TCS (male: $1.096 \mu \mathrm{g} / \mathrm{g}$ creatinine, female: $1.329 \mu \mathrm{g} / \mathrm{g}$ creatinine). Odds ratios (ORs) were calculated using logistic regression analysis for the high TCS exposure and low TCS exposure groups.

Results: Overall, the proportion of participants using personal care products was higher in women than in men. There was a significantly higher proportion of participants in the high TCS exposure group with younger age, higher education and income levels and with more frequent use of fragrance products, hair care products, body cleansers, cosmetics, and antimicrobial agents. In both men and women, ORs tended to increase with increased frequency of use of hair care products, body cleansers, and cosmetics before and after adjustment.

Conclusions: Our findings demonstrate that as the frequency of use of personal care products increases, urine TCS concentration increases. Because TCS is a well-known endocrine disruptor, further studies are needed and explore other health effects with exposure to TCS in general population in Korea.
\end{abstract}

Keywords: Triclosan, Personal care products, Korean National Environmental Health Survey

\section{Background}

Triclosan (TCS), chemical name 5-chloro-2-(2,4-dichlorophenoxy)phenol, is a synthetic antimicrobial and antifungal agent, which is widely used throughout the world. TCS is used mainly as a disinfectant in soaps, detergents, toothpaste, mouthwash, fabrics, deodorant, shampoo, and plastic additives, and it is used in many personal care products, animal products, and industry and household products [1].

\footnotetext{
* Correspondence: drforest@hanmail.net

'Department of Occupational and Environmental Medicine, Kyung Hee University Medical Center, Seoul, South Korea

${ }^{2}$ Department of Occupational and Environmental Medicine, School of

Medicine Kyung Hee University, Seoul, Korea
}

TCS is absorbed into the body through the mouth and skin [2]. TCS is absorbed at a rate of nearly $100 \%$ in the oral cavity, with a half-life of $10-20 \mathrm{~h}$; less than $10 \%$ is absorbed via the transdermal route, with a half-life of 1.4-2.1 days. Absorbed TCS is detected mainly in plasma, urine, and breast milk [3]; it is mostly excreted in the urine [4]. According to a pharmacokinetic study, after oral administration of $4 \mathrm{mg}$ TCS, most was excreted in the urine within the first $24 \mathrm{~h}$ and levels had recovered to baseline within 8 days after administration [5]. These results demonstrate that urinary TCS concentrations can be used as a biomarker of TCS exposure [6]. There have been several studies indicating that

(c) The Author(s). 2019 Open Access This article is distributed under the terms of the Creative Commons Attribution 4.0 International License (http://creativecommons.org/licenses/by/4.0/), which permits unrestricted use, distribution, and reproduction in any medium, provided you give appropriate credit to the original author(s) and the source, provide a link to the Creative Commons license, and indicate if changes were made. The Creative Commons Public Domain Dedication waiver (http://creativecommons.org/publicdomain/zero/1.0/) applies to the data made available in this article, unless otherwise stated. 
urinary TCS concentrations are associated with the use of personal care products containing TCS [6-8].

TCS is known to be an endocrine disruptor that is structurally similar to polychlorinated biphenyls, bisphenol A, dioxins, and thyroid hormones [9]. TCS increases estradiol (E2) and progesterone secretion [10], has a similar effect as estrogen [11], and can induce hypothyroxinemia [12]. Moreover, in experiments with mice, rats, and hamsters, TCS has been associated with liver tumors [4]. Contact dermatitis, photosensitivity, contact dermatitis, skin irritation, and other conditions have also been reported in association with TCS $[13,14]$.

Because of these health problems, various regulations have recently been established in relation to TCS in many countries. Various studies on TCS exposure levels have also been carried out. However, studies on TCS levels in Korea and related factors have not yet been conducted. In this study, we used a nationally representative data for the general population in Korea to analyze the level of TCS exposure in the general population according to the frequency of use of personal care products, which are the main exposure source of TCS.

\section{Material and methods}

\section{Study participants}

This study was based on data of the Second Korean National Environmental Health Survey (KoNEHS 20122014). According to Article 14 of the Environmental Health Act, the KoNEHS is conducted every 3 years to investigate the human exposure levels of harmful environmental factors in the Korean population, explore the influencing factors, and continuously investigate the spatial and temporal distribution and change in these factors [15].

The survey area consisted of 16 cities and provinces nationwide. For the survey sample, the enumeration districts of the National Population and Housing Census 2010 were used for the sample population with the initial stratification classified by local administration. Secondary stratification was according to socioeconomic factors, using stratified multistage cluster sampling applied with proportional allocation of the square root of the population to extract 400 sample enumeration districts [16]. Approximately 15 people from each sample enumeration district were surveyed, targeting a total of 6478 Koreans aged 19 years and older. The survey consisted of an environmental exposure-related questionnaire, clinical testing, and analysis of harmful environmental substances in biological samples [15].

In this study, after excluding 190 participants with missing urinary TCS concentration data, 6288 participants (2692 men, 3596 women) were included from among a total of 6478 participants.

\section{Variables Variables of interest}

To determine the association between TCS exposure and frequency of personal care products use, the frequency of use was classified as used rarely, less than once a week, and more than once a week. Personal care products were classified as hair care products, body cleansers, make-up products, nail care products, antibacterial agents, and fragrance products. Hair care products referred to products such as waxes, gels, and sprays. Body cleansers included foam cleansers, body wash, and shampoo, but not soap. Make-up products included cosmetic products other than basic cosmetics, such as skin care products and lotions; sun block products were also included. Antimicrobial agents refer to liquid-type antibacterial or sterilizing products [17].

Sociodemographic variables and health behavior-related variables of participants were analyzed as follows. Age and body mass index (BMI) were averaged as sociodemographic variables. Education level was classified as below a middle school graduate level, high school graduate level, or college graduate and above. Marital status was classified as unmarried, married, or other (divorced, widowed, separated), and socioeconomic status was classified into quartiles according to household income. Participants were classified as never, former or current smokers and alcohol drinkers. Participants were also categorized according to physical activity level as regularly performing no exercise, moderate exercise, or vigorous exercise.

\section{Urinary triclosan}

Urinary TCS concentration was measured using ultra performance liquid chromatography - tandem mass spectrometry (UPLC-MS/MS) with the Xevo TQ-S (Waters Corporation, Milford, MA, USA) using a spot urine sample [18]. After hydrolyzing each urine sample with ß-glucuronidase/arylsulfatase-degrading enzyme, the metabolites of TCS were extracted with ethyl ether and measured. The measuring principle of TCS concentration was to apply a calibration curve prepared by the standard addition method with using standard solution to the sample. For the precision control in the whole analysis process, relative standard deviation (RSD) of two samples of low dose of standard solution should be less than $15 \%$ for within batch and 20\% for between batch. Quality control (QC) sample was used for the accuracy control in the analysis process. The concentrations less than the method detection limit (MDL, $0.500 \mu \mathrm{g} / \mathrm{L}$ ) were substituted with values of MDL divided by the square root of 2 . The final TCS concentration for statistical analysis was calculated after adjusting urinary creatinine concentration. 


\section{Statistical analysis}

The frequency and proportion of each variable were presented after stratification by gender to determine the general characteristics of participants. First, participants were divided into a high TCS exposure group and low TCS exposure group, based on the top 75th percentile concentration of urinary TCS (male: $1.096 \mu \mathrm{g} / \mathrm{g}$ creatinine, female: $1.329 \mu \mathrm{g} / \mathrm{g}$ creatinine). The frequency and proportion of each variable were then determined by gender. Chi-square tests were performed to analyze the difference in the distribution of each variable. Odds ratios (ORs) and 95\% confidence intervals (CIs) were calculated using logistic regression for the high TCS exposure and low TCS exposure groups. Unadjusted models are presented and a multivariate adjusted model was adjusted for age, BMI, socioeconomic variables, and health behavior-related variables. IBM SPSS version 19 for Windows (SPSS Inc., Chicago, IL, USA) was used for statistical analysis and the statistical significance level was set at $p<0.05$.

\section{Results}

The distribution of the independent variables in the present study was as follows (Table 1). A total 2692 (42.8\%) participants were male, and 3596 (57.2\%) were female. A greater percentage of men than women were college graduates or higher, and more men than women were current drinkers and smokers. In terms of fragrance products, hair care products, nail care products, antimicrobial agents, and air fresheners usage, more than half of men and women responded that they rarely used these products. More than half of men said they rarely used cosmetics and body cleansers, whereas more than half of women reported using these products once a week.

Urine TCS concentration was determined according to high and low TCS exposure groups, based on the upper 75th percentile concentration; the distribution of independent variables is presented in Table 2. The average age in the high TCS exposure group was significantly lower than that in the low exposure group. Furthermore, the urinary TCS concentration tended to decrease as age increased (See Additional file 1: Table S1). For both genders, the proportions of college graduates and participants with household income in the third quartile or higher, were significantly greater in the high TCS exposure group than in the low exposure group; the proportions of current drinkers and participants who vigorously exercised were also higher in the high TCS exposure group. Distribution by frequency of use of personal care products showed that for both genders, perfumes, hair care products, body cleansers, cosmetics, and antimicrobial agents were used more frequently in the high TCS exposure group than in the low exposure group. Additionally, more women in the high TCS exposure group reported more frequent use of nail care products.

Logistic regression analysis was applied to determine the degree of association between the frequency of personal care products use and urinary TCS concentration according to low TCS and high TCS exposure groups (Table 3). In the case of men, fragrance products, hair care products, body cleansers, and cosmetics showed significantly higher ORs for use more than once a week versus rarely use: 1.52 (95\% CI 1.16-1.98), 1.50 (95\% CI 1.19-1.87), 1.67 (95\% CI 1.33-2.08), and 1.60 (95\% CI 1.19-2.15), respectively. In the case of women, hair care products, body cleansers, and cosmetics showed significantly higher ORs for use more than once a week versus rarely use of these products: 1.20 (95\% CI 1.01-1.42), 1.28 (95\% CI 1.04-1.58), and 1.33 (95\% CI 1.08-1.65), respectively. Interestingly, ORs were higher in men than in women.

\section{Discussion}

In this study, general characteristics for high urinary TCS concentration were younger age, higher educational level, higher household income level, drinkers, and vigorous exercise group. In a previous study in Canada, higher urinary TCS concentrations were found among women with higher education and income levels, with higher TCS exposure levels in those over 25 years of age than in those under age 25 years [19]. In the United States (US), a study among the general population showed that the higher the income, the higher the concentration of urinary TCS, in relation to age, with the highest concentrations among participants in their 30s; concentrations then gradually decreased with age [2]. On the other hand, according to a study conducted in Korea in 2009, older age and lower income levels were associated with higher urinary TCS concentration with no significant difference [20]. Explanations for the differing results among studies may be owing to differences in lifestyles, such as different frequency of use of TCS-containing consumer products; additional research is needed to clarify these differences in study findings [20]. There has been no confirmation of the common trend found among studies regarding characteristics of drinking, smoking, exercise, and BMI of participants. The high TCS exposure among young adults aged $20-30$ years is important in that it can be associated with pregnancy and childbirth. TCS is an endocrine disruptor and several animal studies have found that it can affect thyroid hormone homeostasis [1]. Because thyroid hormones are essential for development of the fetal nervous system and differentiation of the brain, deficiency of thyroid hormones can cause fetal neurodevelopmental problems [21-23]. 
Table 1 Basic characteristics according to sociodemographic factors and several exposure factros to triclosan in study population

\begin{tabular}{|c|c|c|c|c|}
\hline Category & & Total $(n=6288)$ & Male $(n=2692)$ & Female $(n=3596)$ \\
\hline Triclosan level ( $\mu \mathrm{g} / \mathrm{L})$ & & $0.35(0.35-1.21)$ & $0.35(0.35-1.09)$ & $0.35(0.35-1.33)$ \\
\hline Age (years) & & $51.6(15.1)$ & $51.7(15.5)$ & $51.4(14.8)$ \\
\hline BMI $\left(\mathrm{kg} / \mathrm{m}^{2}\right)$ & & $24.3(3.4)$ & $24.6(3.2)$ & $24.1(3.5)$ \\
\hline \multirow[t]{3}{*}{ Education } & $\leq$ Middle school & $2207(35.1)$ & $762(28.3)$ & $1445(40.2)$ \\
\hline & High school & $1901(30.2)$ & $822(30.5)$ & $1079(30.0)$ \\
\hline & $\geq$ College & $2180(34.7)$ & $1108(41.2)$ & $1072(29.8)$ \\
\hline \multirow[t]{3}{*}{ Marital status } & Single & $632(10.0)$ & $346(12.9)$ & $286(7.9)$ \\
\hline & Married & $4992(79.4)$ & $2213(82.2)$ & $2779(77.3)$ \\
\hline & Others & $664(10.6)$ & $133(4.9)$ & $531(14.8)$ \\
\hline \multirow[t]{4}{*}{ Household income } & 1st quartile & $1767(28.1)$ & 769 (28.6) & 998 (27.8) \\
\hline & 2nd quartile & $2900(46.1)$ & $1261(46.8)$ & $1639(45.6)$ \\
\hline & 3rd quartile & $1563(24.9)$ & $634(23.6)$ & $929(25.8)$ \\
\hline & 4th quartile & $58(0.9)$ & $28(1.0)$ & $30(0.8)$ \\
\hline \multirow[t]{3}{*}{ Smoking } & None & $4147(66.0)$ & $742(27.6)$ & $3405(94.7)$ \\
\hline & Ex-smoker & $1028(16.3)$ & 964 (35.8) & $64(1.8)$ \\
\hline & Current-smoker & $1013(17.7)$ & 986 (36.6) & $127(3.5)$ \\
\hline \multirow[t]{3}{*}{ Alcohol } & None & $2153(34.2)$ & $429(15.9)$ & $1724(47.9)$ \\
\hline & Ex & $412(6.6)$ & $274(10.2)$ & $138(3.9)$ \\
\hline & Current & $3723(59.2)$ & 1989 (73.9) & $1734(48.2)$ \\
\hline \multirow[t]{3}{*}{ Exercise } & No & 3307 (52.6) & 1309 (48.6) & $1998(55.6)$ \\
\hline & Moderate & 709 (11.3) & $284(10.6)$ & $425(11.8)$ \\
\hline & Vigorous & $2272(36.1)$ & 1099 (40.8) & $1173(32.6)$ \\
\hline \multirow[t]{3}{*}{ Fragrance products } & Rarely & $5023(79.9)$ & 2269 (84.3) & $2754(76.6)$ \\
\hline & $<$ Once a week & $403(6.4)$ & $122(4.5)$ & $281(7.8)$ \\
\hline & $\geq$ Once a week & $862(13.7)$ & 301 (11.2) & $561(15.6)$ \\
\hline \multirow[t]{3}{*}{ Hair care products } & Rarely & $3838(61.1)$ & $1948(72.4)$ & $1890(52.5)$ \\
\hline & $<$ Once a week & $732(11.6)$ & $251(9.3)$ & $481(13.4)$ \\
\hline & $\geq$ Once a week & $1718(27.3)$ & $493(18.3)$ & $1225(34.1)$ \\
\hline \multirow[t]{3}{*}{ Body cleansers } & Rarely & $2958(47.0)$ & 1902 (70.7) & $1056(29.4)$ \\
\hline & $<$ Once a week & $110(1.8)$ & $46(1.7)$ & $64(1.8)$ \\
\hline & $\geq$ Once a week & $3220(51.2)$ & $744(27.6)$ & $2476(68.8)$ \\
\hline \multirow[t]{3}{*}{ Cosmetics } & Rarely & $3154(50.2)$ & $2381(88.5)$ & $773(21.5)$ \\
\hline & $<$ Once a week & $252(4.0)$ & $81(3.0)$ & $171(4.8)$ \\
\hline & $\geq$ Once a week & $2882(45.8)$ & $230(8.5)$ & $2652(73.7)$ \\
\hline \multirow[t]{3}{*}{ Nail care products } & Rarely & $5325(84.7)$ & 2681 (99.6) & $2644(73.5)$ \\
\hline & $<$ Once a week & $678(10.8)$ & $8(0.3)$ & $670(18.6)$ \\
\hline & $\geq$ Once a week & $285(4.5)$ & $3(0.1)$ & $282(7.9)$ \\
\hline \multirow[t]{3}{*}{ Antimicrobial agents } & Rarely & $5234(83.2)$ & $2320(86.2)$ & 2914 (81.0) \\
\hline & $<$ Once a week & $213(3.4)$ & $57(2.1)$ & $156(4.4)$ \\
\hline & $\geq$ Once a week & $841(13.4)$ & $315(11.7)$ & $526(14.6)$ \\
\hline \multirow[t]{3}{*}{ Air freshener } & Rarely & $4673(74.3)$ & $2017(74.9)$ & $2656(73.9)$ \\
\hline & $<$ Once a week & $231(3.7)$ & $73(2.7)$ & $158(4.4)$ \\
\hline & $\geq$ Once a week & $1384(22.0)$ & $602(22.4)$ & $782(21.7)$ \\
\hline
\end{tabular}


Table 2 Basic characteristics of study population in both high ${ }^{a}$ (the top 75th percentile) and low urinary concentration of triclosan group by gender

\begin{tabular}{|c|c|c|c|c|c|c|c|}
\hline \multirow{2}{*}{ Category } & & \multicolumn{3}{|l|}{ Male } & \multicolumn{3}{|l|}{ Female } \\
\hline & & Low $(n=2016)$ & High $(n=676)$ & $p$ value & Low $(n=2696)$ & High $(n=900)$ & $p$ value \\
\hline Age (years) & & $52.6(15.3)$ & $49.0(15.9)$ & $<0.0001$ & $52.3(14.7)$ & $48.8(14.7)$ & $<0.0001$ \\
\hline BMI $\left(\mathrm{kg} / \mathrm{m}^{2}\right)$ & & $24.5(3.1)$ & $24.7(3.3)$ & 0.219 & $24.1(3.5)$ & $23.9(3.5)$ & 0.034 \\
\hline \multirow[t]{3}{*}{ Education } & $\leq$ Middle school & $618(30.6)$ & $144(21.3)$ & $<0.0001$ & $1162(43.1)$ & $283(31.4)$ & $<0.0001$ \\
\hline & High school & $633(31.4)$ & $189(28.0)$ & & $783(29.0)$ & $296(32.9)$ & \\
\hline & $\geq$ College & 765 (38.0) & $343(50.7)$ & & $751(27.9)$ & $321(35.7)$ & \\
\hline \multirow[t]{3}{*}{ Marital status } & Single & $234(11.6)$ & $112(16.6)$ & 0.003 & $187(6.9)$ & 99 (11.0) & $<0.0001$ \\
\hline & Married & $1678(83.2)$ & $535(79.1)$ & & $2088(77.5)$ & $691(76.8)$ & \\
\hline & Others & $104(5.2)$ & $29(4.3)$ & & $421(15.6)$ & $110(12.2)$ & \\
\hline \multirow[t]{4}{*}{ Household income } & 1st quartile & $598(29.6)$ & $171(29.3)$ & 0.039 & $790(29.3)$ & $208(23.1)$ & $<0.0001$ \\
\hline & 2nd quartile & $947(47.0)$ & $314(46.4)$ & & $1223(45.4)$ & $416(46.2)$ & \\
\hline & 3rd quartile & $451(22.4)$ & $183(27.1)$ & & $663(24.6)$ & $266(29.6)$ & \\
\hline & 4th quartile & $20(1.0)$ & $8(1.2)$ & & $20(0.7)$ & $10(1.1)$ & \\
\hline \multirow[t]{3}{*}{ Smoking } & None & $552(27.4)$ & $190(28.2)$ & 0.898 & 2551 (94.6) & $854(94.9)$ & 0.135 \\
\hline & Ex-smoker & $721(35.8)$ & $243(35.9)$ & & $43(1.6)$ & $21(2.3)$ & \\
\hline & Current smoker & $743(36.8)$ & $243(35.9)$ & & $102(3.8)$ & $25(2.8)$ & \\
\hline \multirow[t]{3}{*}{ Alcohol } & None & $333(16.5)$ & $96(14.2)$ & $<0.0001$ & $1323(49.1)$ & $401(44.5)$ & 0.036 \\
\hline & Ex & $227(11.3)$ & $47(6.9)$ & & $96(3.6)$ & $42(4.7)$ & \\
\hline & Current & $1456(72.2)$ & $533(78.9)$ & & $1277(47.3)$ & $457(50.8)$ & \\
\hline \multirow[t]{3}{*}{ Exercise } & No & $1007(49.9)$ & $302(44.7)$ & 0.029 & $1538(57.0)$ & $460(51.1)$ & 0.005 \\
\hline & Moderate & $215(10.7)$ & $69(10.2)$ & & $300(11.1)$ & $125(13.9)$ & \\
\hline & Vigorous & $794(39.4)$ & $305(45.1)$ & & $858(31.9)$ & $315(35.0)$ & \\
\hline \multirow[t]{3}{*}{ Fragrance products } & Rarely & $1740(86.3)$ & $529(78.3)$ & $<0.0001$ & $2106(78.1)$ & $648(72.0)$ & $<0.0001$ \\
\hline & $<$ Once a week & $83(4.1)$ & $39(5.8)$ & & $192(7.1)$ & $89(9.9)$ & \\
\hline & $\geq$ Once a week & $193(9.6)$ & $108(15.9)$ & & $398(14.8)$ & $163(18.1)$ & \\
\hline \multirow[t]{3}{*}{ Hair care products } & Rarely & $1510(74.9)$ & $438(64.8)$ & $<0.0001$ & $1442(53.5)$ & $448(49.8)$ & 0.113 \\
\hline & $<$ Once a week & $179(8.9)$ & $72(10.6)$ & & $360(13.3)$ & $121(13.4)$ & \\
\hline & $\geq$ Once a week & $327(16.2)$ & $166(24.6)$ & & $894(33.2)$ & 331 (36.8) & \\
\hline \multirow[t]{3}{*}{ Body cleansers } & Rarely & $1496(74.2)$ & $406(60.1)$ & $<0.0001$ & $858(31.8)$ & $198(22.0)$ & $<0.0001$ \\
\hline & $<$ Once a week & $13(1.6)$ & $13(1.9)$ & & $49(1.8)$ & $15(1.7)$ & \\
\hline & $\geq$ Once a week & $487(24.2)$ & $257(38.0)$ & & $1789(66.4)$ & $687(76.3)$ & \\
\hline \multirow[t]{3}{*}{ Cosmetics } & Rarely & $1814(90.0)$ & $567(83.9)$ & $<0.0001$ & $629(23.3)$ & $144(16.0)$ & $<0.0001$ \\
\hline & $<$ Once a week & $56(2.8)$ & $25(3.7)$ & & $136(5.0)$ & $35(3.9)$ & \\
\hline & $\geq$ Once a week & $146(7.2)$ & $84(12.4)$ & & 1931 (71.6) & $721(80.1)$ & \\
\hline \multirow[t]{3}{*}{ Nail care products } & Rarely & 2007 (99.5) & $674(99.7)$ & 0.604 & $2024(75.1)$ & $620(68.9)$ & 0.001 \\
\hline & $<$ Once a week & $6(0.3)$ & $2(0.3)$ & & 469 (17.4) & $201(22.3)$ & \\
\hline & $\geq$ Once a week & $3(0.2)$ & $0(0.0)$ & & $203(7.5)$ & $79(8.8)$ & \\
\hline \multirow[t]{3}{*}{ Antimicrobial agents } & Rarely & $1763(87.4)$ & $557(82.4)$ & 0.004 & $2215(82.2)$ & $699(77.7)$ & 0.008 \\
\hline & $<$ Once a week & $38(1.9)$ & $19(2.8)$ & & $114(4.2)$ & $42(4.7)$ & \\
\hline & $\geq$ Once a week & $215(10.7)$ & $100(14.8)$ & & $367(13.6)$ & $159(17.6)$ & \\
\hline \multirow[t]{3}{*}{ Air fresheners } & Rarely & $1517(75.3)$ & $500(73.9)$ & 0.55 & $2014(74.7)$ & $642(71.3)$ & 0.13 \\
\hline & $<$ Once a week & $57(2.8)$ & $16(2.4)$ & & $113(4.2)$ & $45(5.0)$ & \\
\hline & $\geq$ Once a week & $442(21.9)$ & $160(23.7)$ & & $569(21.1)$ & $213(23.7)$ & \\
\hline
\end{tabular}

\footnotetext{
${ }^{a}$ Male: $\geq 1.096 \mu \mathrm{g} / \mathrm{g}$ creatinine, female: $\geq 1.329 \mu \mathrm{g} / \mathrm{g}$ creatinine, data are mean (standard deviation), or number (\%)
} 
Table 3 Odds ratios (OR) and 95\% confidence intervals (Cl) relating personal care products usage of high urinary concentration of triclosan (male: $\geq 1.096 \mu \mathrm{g} / \mathrm{g}$ creatinine, female: $\geq 1.329 \mu \mathrm{g} / \mathrm{g}$ creatinine) compared to low urinary concentration of triclosan

\begin{tabular}{|c|c|c|c|c|}
\hline \multirow[b]{2}{*}{ Category } & \multicolumn{2}{|l|}{ Male } & \multicolumn{2}{|l|}{ Female } \\
\hline & Unadjusted & Multivariate adjusted model & Unadjusted & Multivariate adjusted model \\
\hline \multicolumn{5}{|l|}{ Fragrance products } \\
\hline Rarely & 1.00 & 1.00 & 1.00 & 1.00 \\
\hline$<$ Once a week & $1.55(1.04-2.29)$ & $1.39(0.93-2.07)$ & $1.51(1.15-1.97)$ & $1.27(0.97-1.67)$ \\
\hline$\geq$ Once a week & $1.84(1.43-2.38)$ & $1.52(1.16-1.98)$ & $1.33(1.09-1.63)$ & $1.05(0.84-1.30)$ \\
\hline \multicolumn{5}{|l|}{ Hair care products } \\
\hline Rarely & 1.00 & 1.00 & 1.00 & 1.00 \\
\hline$<$ Once a week & $1.39(1.03-1.86)$ & $1.39(1.03-1.87)$ & $1.08(0.86-1.36)$ & $1.21(0.96-1.54)$ \\
\hline$\geq$ Once a week & $1.75(1.41-2.17)$ & $1.50(1.19-1.87)$ & $1.19(1.01-1.41)$ & $1.20(1.01-1.42)$ \\
\hline \multicolumn{5}{|l|}{ Body cleansers } \\
\hline Rarely & 1.00 & 1.00 & 1.00 & 1.00 \\
\hline$<$ Once a week & $1.45(0.76-2.78)$ & $1.20(0.62-2.32)$ & $1.33(0.73-2.41)$ & $1.20(0.66-2.20)$ \\
\hline$\geq$ Once a week & $1.95(1.61-2.34)$ & $1.67(1.33-2.08)$ & $1.66(1.39-1.99)$ & $1.28(1.04-1.58)$ \\
\hline \multicolumn{5}{|l|}{ Cosmetics } \\
\hline Rarely & 1.00 & 1.00 & 1.00 & 1.00 \\
\hline$<$ Once a week & $1.43(0.88-2.31)$ & $1.21(0.74-1.98)$ & $1.12(0.74-1.70)$ & $1.04(0.68-1.58)$ \\
\hline$\geq$ Once a week & $1.84(1.39-2.45)$ & $1.60(1.19-2.15)$ & $1.63(1.33-1.99)$ & $1.33(1.08-1.65)$ \\
\hline \multicolumn{5}{|l|}{ Nail care products } \\
\hline Rarely & 1.00 & 1.00 & 1.00 & 1.00 \\
\hline$<$ Once a week & $0.99(0.20-4.93)$ & $1.06(0.21-5.30)$ & $1.40(1.16-1.69)$ & $1.26(1.04-1.53)$ \\
\hline$\geq$ Once a week & - & - & $1.27(0.97-1.67)$ & $1.13(0.85-1.50)$ \\
\hline \multicolumn{5}{|l|}{ Antimicrobial agents } \\
\hline Rarely & 1.00 & 1.00 & 1.00 & 1.00 \\
\hline$<$ Once a week & $1.58(0.91-2.77)$ & $1.43(0.81-2.52)$ & $1.17(0.81-1.68)$ & $0.98(0.67-1.42)$ \\
\hline$\geq$ Once a week & $1.47(1.14-1.90)$ & $1.27(0.98-1.65)$ & $1.37(1.12-1.69)$ & $1.17(0.95-1.44)$ \\
\hline \multicolumn{5}{|l|}{ Air fresheners } \\
\hline Rarely & 1.00 & 1.00 & 1.00 & 1.00 \\
\hline$<$ Once a week & $0.85(0.49-1.50)$ & $0.82(0.47-1.46)$ & $1.25(0.87-1.79)$ & $1.20(0.84-1.72)$ \\
\hline$\geq$ Once a week & $1.10(0.89-1.35)$ & $0.96(0.78-1.20)$ & $1.17(0.98-1.41)$ & $1.03(0.85-1.24)$ \\
\hline
\end{tabular}

Multivariate adjusted model: adjusted with age, BMI, education, marital status, household income, alcohol intake, exercise, and smoking

According to analysis of the relationship between the frequency of use of personal care products and urinary TCS concentration, we found that the frequency of use of hair care products, body cleansers, and cosmetics were consistently related to urinary TCS concentration in both men and women. In the upper 75th percentile of urinary TCS concentration, the proportion of more frequent products use was higher than among participants with rarely products use and ORs were higher in participants who used these products more often. Similar results were found in a study of breastfeeding mothers in Sweden. Mothers who used personal care products containing TCS showed significantly higher breast milk and plasma TCS concentrations than those who did not use these products [8]. In addition, men showed higher ORs than women. Men tend to use less personal care products compared to women, which may be the cause of the larger differences between used and unused groups. These results suggest that personal care products are a major source of TCS exposure.

As a result of analyzing a list of the raw materials of cosmetics reported to the Korea Food \& Drug Administration (KFDA) by domestic manufacturers in 2015, 127 of the 100,190 (0.13\%) cosmetics products manufactured in Korea were found to have used TCS [24]. It has been found that TCS is mainly used in products that are rinsed off after use, such as body cleansers and foam cleansers [24]. According to US data in 2010, 28 of 3359 eye make-up products, 10 of 4345 facial make-up products, 226 of 3070 body cleansing products, 3 of 5242 
hair care products, and 42 of 2842 fragrance products contained TCS [25]. TCS is mainly found in body cleansing products and it is thought that exposure via these products is high. A smaller number of cosmetics and hair care products contain TCS, but these can result in direct exposure and TCS-containing cleansing products are often used to remove cosmetics. Therefore, urine TCS concentrations may be high depending on the use frequency of cosmetics and hair care products.

According to the results of previous studies both on TCS toxicity in humans and use of personal care products as the main exposure source of TCS, regulations on the use of TCS for personal care products have been established in many countries. In Korea, KFDA launched a new regulation with TCS concentration in personal care products, such as, body cleansing products that are rinsed off after use, deodorants (excluding spray products), face powder, and foundation like concealer, that the concentration limit of TCS in personal care products was $0.3 \%$; moreover, TCS could not be used in toothpaste and mouthwash in 2015 [24]. In Europe, the concentration limit of TCS in mouthwash was $0.2 \%$ and that in other personal hygiene products was $0.3 \%$. In the case of Japan, the concentration limit of TCS in all products $0.1 \%$ [24]. Although TCS regulation has started in many countries, some cosmetics and human body cleansing products still contain TCS and these products still can be purchased in countries with no regulations in place. Regulatory concentrations are set at levels that are harmless to the human body [24]; however, women of childbearing age, children, and adolescents should select products that do not contain TCS or should rinse them off thoroughly after use. It is especially important to be careful when purchasing mouthwash in some foreign countries because nearly $100 \%$ of TCS can be absorbed in the oral cavity [3].

In the present study, similar to those of other countries, we found a tendency for urinary TCS concentration to increase in younger age, higher income level and education level. The present study findings also confirmed that personal care products represent the main cause of TCS exposure. People with higher levels of income and education tend to have greater interest in personal hygiene and tend to purchase personal care products, which may lead to increased exposure to chemicals such as TCS. Likewise, young people in their 20s and 30s are more concerned about personal care than children, adolescents, and elderly adults; therefore, this young population is more exposed to TCS through greater use of personal care products. TCS in women of childbearing age can be a potential neurotoxic agent for the fetus during pregnancy [26] and can be delivered to infants through breast milk. Infants and young children are highly susceptible to toxic substances as they have rapid rates of body organ development and their processes of detoxification of toxic substances are less developed [27]. Therefore, additional research is needed to determine whether current levels of regulation are appropriate for these susceptible population.

The limitations of this study are as follows. First, we did not identify the usage amount of personal care products, only the frequency of use. Second, we did not consider the simultaneous use of other personal care products, use of other personal care products not included in the survey, and other TCS exposure factors apart from personal care products. Third, in about $60 \%$ of participants, urinary TCS concentration was measured below the detection limit. However, it did not affect the statistical analysis of this study. Fourth, the health effects of increased urinary TCS concentration were not analyzed. Despite these limitations, this study suggested the exposure level of TCS and the relationship with use of personal care products, which are major exposure sources of TCS using a representative data in Korean population.

Regulation of TCS was initiated in Korea in 2015 and it is expected that the effect of reduction of TCS exposure by the regulation will be confirmed through the analysis of third KoNEHS data, which was conducted in 2015-2017 and not publically released yet. Furthermore, children over three years old were included in the study population in the third KoNEHS, therefore, the TCS exposure level and health effects could be studied in the susceptible population. Based on future studies, it could confirm the effect of the regulation and suggest another more powerful policy to minimize TCS exposure in Korean population.

\section{Conclusion}

This study found out the association of the use of personal care products and the concentration of urinary TCS in general population in Korea. According to this study, the levels of urinary TCS were higher in female, younger people, and higher-income people. Because TCS is a well-known endocrine disruptor and several health problems related with exposure to TCS have suggested, further studies are needed to monitor the trend of urinary TCS level and explore other health effects with exposure to TCS in general population in Korea using a representative data for general population.

\section{Additional file}

Additional file 1: Medians (interquartile range) of Urinary TCS concentration according to age. The urinary TCS concentration tended to decrease as age increased. (XLSX $11 \mathrm{~kb}$ ) 


\section{Abbreviations}

BMl: Body mass index; Cl: Confidence interval; KoNEHS: Korean National Environmental Health Survey; OR: Odds ratio; TCS: Triclosan

\section{Acknowledgements}

There is no conflict of interest or financial support to declare.

\section{Funding}

Not applicable.

\section{Availability of data and materials}

The data of the KoNEHS is opened to the public, therefore, any researcher can be obtained after request from the website http://meta.narastat.kr/ metasvc/svc/SvcMetaDcDtaPopup.do?confmNo=106027\&inputYear=2012.

\section{Authors' contributions}

MP designed this study and wrote a draft of this manuscript. SK, YK, and DJN analyzed the data. JR provided technical support. SL performed critical revision of the manuscript. All authors read and approved the final manuscript.

\section{Ethics approval and consent to participate}

Not applicable.

\section{Consent for publication}

Not applicable.

\section{Competing interests}

The authors declare that they have no competing interests.

\section{Publisher's Note}

Springer Nature remains neutral with regard to jurisdictional claims in published maps and institutional affiliations.

\section{Received: 31 August 2018 Accepted: 22 January 2019}

Published online: 28 January 2019

\section{References}

1. Dann AB, Hontela A. Triclosan: environmental exposure, toxicity and mechanisms of action. J Appl Toxicol. 2011;31(4):285-311.

2. Calafat AM, Ye X, Wong LY, Reidy JA, Needham LL. Urinary concentrations of triclosan in the U.S. population: 2003-2004. Environ Health Perspect. 2008 116(3):303-7.

3. Cullinan MP, Palmer JE, Carle AD, West MJ, Westerman B, Seymour GJ. The influence of a triclosan toothpaste on adverse events in patients with cardiovascular disease over 5-years. Sci Total Environ. 2015;508:546-52.

4. Rodricks JV, Swenberg JA, Borzelleca JF, Maronpot RR, Shipp AM. Triclosan: a critical review of the experimental data and development of margins of safety for consumer products. Crit Rev Toxicol. 2010;40(5):422-84.

5. Sandborgh-Englund G, Adolfsson-Erici M, Odham G, Ekstrand J. Pharmacokinetics of triclosan following oral ingestion in humans. J Toxicol Environ Health A. 2006;69(20):1861-73.

6. Den Hond E, Paulussen M, Geens T, Bruckers L, Baeyens W, David F, et al. Biomarkers of human exposure to personal care products: results from the Flemish Environment and Health Study (FLEHS 2007-2011). Sci Total Environ. 2013:463-464:102-10

7. Allmyr M, Harden F, Toms LM, Mueller JF, McLachlan MS, Adolfsson-Erici M, et al. The influence of age and gender on triclosan concentrations in Australian human blood serum. Sci Total Environ. 2008;393(1):162-7.

8. Allmyr M, Adolfsson-Erici M, McLachlan MS, Sandborgh-Englund G. Triclosan in plasma and milk from Swedish nursing mothers and their exposure via personal care products. Sci Total Environ. 2006;372(1):87-93.

9. Crofton KM, Paul KB, Devito MJ, Hedge JM. Short-term in vivo exposure to the water contaminant triclosan: evidence for disruption of thyroxine. Environ Toxicol Pharmacol. 2007;24(2):194-7.

10. Gee RH, Charles A, Taylor N, Darbre PD. Oestrogenic and androgenic activity of triclosan in breast cancer cells. J Appl Toxicol. 2008;28(1):78-91.

11. Henry ND, Fair PA. Comparison of in vitro cytotoxicity, estrogenicity and anti-estrogenicity of triclosan, perfluorooctane sulfonate and perfluorooctanoic acid. J Appl Toxicol. 2013;33(4):265-72.
12. Helbing $C C$, van Aggelen $G$, Veldhoen N. Triclosan affects thyroid hormonedependent metamorphosis in anurans. Toxicol Sci. 2011;119(2):417-8 author reply 9-22.

13. Durbize E, Vigan M, Puzenat E, Girardin P, Adessi B, Desprez PH, et al. Spectrum of cross-photosensitization in 18 consecutive patients with contact photoallergy to ketoprofen: associated photoallergies to nonbenzophenone-containing molecules. Contact Dermatitis. 2003;48(3):144-9.

14. Storer E, Koh KJ, Warren L. Severe contact dermatitis as a result of an antiseptic bath oil. Australas J Dermatol. 2004;45(1):73-5.

15. Yoo J, Choi W, Jeon H, Joo Y, Lee C. Survey overview. Guidelines for using raw materials for Korean National Environmental Health Survey - the second stage ('12-'14). Incheon: Korean national institute of environmental research; 2017. p. 1-5.

16. Yoo J, Choi W, Jeon H, Joo Y, Lee C. Sample design. Guidelines for using raw materials for Korean National Environmental Health Survey - the second stage ('12 '14). Incheon: Korean national institute of environmental research; 2017. p. 6-15.

17. Yoo J, Choi W, Jeon H, Joo Y, Lee C. Survey Items. Guidelines for using raw materials for Korean National Environmental Health Survey - the second stage ('12 '14). Incheon: Korean national institute of environmental research: 2017. p. 28-9.

18. Yoo J, Choi W, Jeon H, Joo Y, Lee C. Analysis manual of environmental noxious materials. Guidelines for using raw materials for Korean National Environmental Health Survey - the second stage ('12-'14). Incheon: Korean national institute of environmental research; 2017. p. 54-67.

19. Arbuckle TE, Marro L, Davis K, Fisher M, Ayotte P, Belanger P, et al. Exposure to free and conjugated forms of bisphenol a and triclosan among pregnant women in the MIREC cohort. Environ Health Perspect. 2015;123(4):277-84.

20. Kim K, Park H, Yang W, Lee JH. Urinary concentrations of bisphenol a and triclosan and associations with demographic factors in the Korean population. Environ Res. 2011;111(8):1280-5.

21. Boas M, Feldt-Rasmussen U, Main KM. Thyroid effects of endocrine disrupting chemicals. Mol Cell Endocrinol. 2012;355(2):240-8.

22. Krassas GE, Poppe K, Glinoer D. Thyroid function and human reproductive health. Endocr Rev. 2010:31(5):702-55.

23. Zoeller TR, Dowling AL, Herzig CT, lannacone EA, Gauger KJ, Bansal R. Thyroid hormone, brain development, and the environment. Environ Health Perspect. 2002;110(Suppl 3):355-61.

24. Cosmetics Research Team. Risk assessment of cosmetics. Cheongju-si: The National Institute of Food and Drug Safety Evaluation, Ministry of Food and Drug Safety; 2017. p. 151-72.

25. Cosmetic Ingredient Review Expert P. Final safety assessment of triclosan. Washington, DC: The cosmetic ingredient review; 2010. p.33-7.

26. Yueh MF, Tukey RH. Triclosan: a widespread environmental toxicant with many biological effects. Annu Rev Pharmacol Toxicol. 2016;56:251-72.

27. Goldman LR. Children-unique and vulnerable. Environmental risks facing children and recommendations for response. Environ Health Perspect. 1995;103(Suppl 6):13-8.

Ready to submit your research? Choose BMC and benefit from

- fast, convenient online submission

- thorough peer review by experienced researchers in your field

- rapid publication on acceptance

- support for research data, including large and complex data types

- gold Open Access which fosters wider collaboration and increased citations

- maximum visibility for your research: over $100 \mathrm{M}$ website views per year

At $\mathrm{BMC}$, research is always in progress.

Learn more biomedcentral.com/submissions 